\title{
Perfil de produção de etanol e trealose em Saccharomyces cerevisiae cultivadas em mosto a base de caldo de cana
}

\author{
Ethanol and trehalose profile production in Saccharomyces cerevisiae grown in wort sugar cane \\ juice base
}

\author{
A. F. da Silva Santos ${ }^{1}$; M. S. Mascarenhas Santos²; F. S. Maia ${ }^{3}$; C. A. L. Cardoso ${ }^{2}$; \\ M. Batistote ${ }^{2}$ \\ ${ }^{1}$ Universidade Federal de Minas Gerais, 31270-901, Belo Horizonte, MG, Brasil \\ ${ }^{2}$ Programa de Pós-graduação em Recursos Naturais, Universidade Estadual de Mato Grosso do Sul, 79804-970, \\ Dourados, MS, Brasil \\ ${ }^{3}$ Universidade Estadual de Mato Grosso do Sul, 79804-970, Dourados, MS, Brasil
}

*maria_mascarenhas@outlook.com

(Recebido em 03 de fevereiro de 2018; aceito em 20 de julho de 2018)

\begin{abstract}
No processo fermentativo as leveduras são expostas a diversos fatores de estresse e, para manter a sua capacidade fermentativa estes microrganismos precisam adaptar-se às mudanças ambientais que ocorrem durante o processo produtivo. Estas adaptações podem refletir em alterações das rotas bioquímicas e, assim, determinar a quantidade dos metabólitos celulares produzidos. Neste sentido, este estudo visa quantificar o perfil de acúmulo de trealose e etanol em linhagens industriais de Saccharomyces cerevisiae submetidas a diferentes condições de fermentação. Foi utilizado o meio YPSAC 5\% para obter aa biomassa celular. Para a avaliação da concentração de etanol e acúmulo de trealose, foi utilizado o mosto na concentração de $15^{\circ}$ Brix nas temperaturas de 30 e $40^{\circ} \mathrm{C}$. A levedura Fleischmann, apresentou o maior acúmulo, de 100 nmoles de trealose/mg de células seca, em 10 horas a $30^{\circ} \mathrm{C}$ em relação às demais leveduras analisadas. $\mathrm{A} 40^{\circ} \mathrm{C}$, as leveduras apresentaram um acúmulo gradativo de trealose ao longo dos tempos de fermentação. Quanto à concentração de etanol a levedura Fleischmann apresentou a maior concentração de etanol de 9,0\% (v/v) em 20 horas de fermentação a $30^{\circ} \mathrm{C}$. A Catanduva-1 apresentou $13,8 \%$ (v/v) de etanol em 40 horas a $30^{\circ} \mathrm{C}$ e a Red Star $10 \%$ (v/v) nos tempos de 10 e 20 horas de fermentação a $30^{\circ} \mathrm{C}$. As maiores alterações da produção de metabólitos foram observadas para as leveduras Catanduva-1 e Red Star, com um acúmulo gradativo de trealose nos tempos analisados e perda de etanol no tempo de 40 horas de fermentação à temperatura de $40^{\circ} \mathrm{C}$. Palavras-chave: estresse fermentativo, metabólitos, carboidrato reserva.
\end{abstract}

In the fermentative process the yeasts are exposed to several stresses factors and in others to maintain their fermentative capacity, these microorganisms must adapt to the environmental changes that occur during the process. These adaptations may reflect changes in biochemical routes and thus determine the amount of cellular metabolites produced. This study aims to quantify the accumulation profile of trehalose and ethanol in industrial strains of Saccharomyces cerevisiae submitted to different fermentation conditions. The 5\% YPSAC medium was used to obtain the cellular biomass. For the evaluation of the ethanol concentration and accumulation of trehalose the must was used in the concentration of $15^{\circ}$ Brix at temperatures of 30 and $40^{\circ} \mathrm{C}$. Fleischmann yeast presented the highest accumulation, of $100 \mathrm{nmoles} / \mathrm{mg}$ of cells, in 10 hours at $30^{\circ} \mathrm{C}$ in relation to the other yeasts analyzed. At $40^{\circ} \mathrm{C}$, the yeasts presented a gradual accumulation of trehalose throughout the fermentation times. As for the yeast ethanol concentration, Fleischmann presented the highest concentration of ethanol of $9.0 \%(\mathrm{v} / \mathrm{v})$ in 20 hours of fermentation at $30^{\circ} \mathrm{C}$. Catanduva-1 presented $13.8 \%$ (v/v) of ethanol in 40 hours at $30{ }^{\circ} \mathrm{C}$ and Red Star $10 \%$ (v/v) at 10 and 20 hours of fermentation at $30{ }^{\circ} \mathrm{C}$. The major alterations in the production of metabolites were observed for Catanduva-1 and Red Star yeasts, with a gradual accumulation of trehalose at the times analyzed and loss of ethanol in 40 hours of fermentation at $40^{\circ} \mathrm{C}$.

Keywords: fermentative stress, metabolites, carbohydrate reserves.

\section{INTRODUÇÃO}

No Brasil a produção de etanol apresenta duas peculiaridades para a fermentação. Uma referese ao substrato ou mosto que, para ser fermentado, não sofre nenhum tratamento no sentido de 
eliminar a microbiota do caldo de cana-de-açúcar [1]. A outra se refere à levedura, que é separada do caldo por centrifugação e passa pelo tratamento ácido por 2 horas para redução da contaminação bacteriana, sendo reutilizada em um novo ciclo fermentativo. Desta forma a levedura pode ser submetida a dois ciclos diários de fermentação por um período de 200 a 250 dias da safra [2]. Este processo de fermentação etanólica ocorre em substrato contendo de 18 a $22 \%$ de açúcares redutores totais (ART) sobre uma biomassa de levedura que resulta em teores alcoólicos de 8 a $10 \%(\mathrm{v} / \mathrm{v})$ obtidos entre 6 a 10 horas de fermentação em temperaturas de 32 a $38^{\circ} \mathrm{C}$ [2].

No processo fermentativo as leveduras são expostas a diversos tipos de estresses, tais como deficiência nutricional do substrato, temperatura, contaminação bacteriana, concentração de açúcares e sais, acidez e outros que porventura são decorrentes do próprio metabolismo da levedura $[3,2]$ e, para manter a capacidade fermentativa estes microrganismos precisam adaptar-se às condições adversas do ambiente onde estão inseridas. O tratamento ácido utilizado para minimizar a contaminação bacteriana apresenta-se como um fator de estresse para a levedura, pois as células utilizam os carboidratos de reserva, trealose e glicogênio para manter sua integridade celular frente ao estresse [4]. Com isso, tanto a fisiologia como a desempenho fermentativo das leveduras podem sofrer alterações, perdurando por vários ciclos do processo [5]. A produção de metabólitos intracelulares tais como a trealose, os gliceróis, dentre outros, pode estar relacionada diretamente com os mecanismos adaptativos ou de defesa destas células em virtude da ação do estresse fermentativo [6].

As leveduras industriais apresentam mecanismos de resposta às condições de estresse e se adaptam rapidamente a esses fatores externos adversos ajustando seu metabolismo para evitar a perda de viabilidade celular bem como uma possível alteração no acúmulo dos carboidratos de reserva [7]. Com isso, a trealose pode ser acumulada um pouco antes das células entrarem na fase logarítmica de crescimento, sugerindo ainda que o sinergismo entre os fatores oscilação de temperaturas e alta concentração de etanol propiciam uma resposta da levedura aos fatores de estresse como descrito por François et al. (2012) [8].

Neste sentido, as leveduras que possuem a capacidade de fermentar em altas concentrações de substratos podem acumular quantidades consideradas altas de trealose [5]. Para Trevisol et al. (2011) [9], este composto é necessário por estar envolvido na longevidade celular e na eficiência fermentativa, já que a trealose permite maior concentração de etanol e pode estar envolvido na proteção contra a oxidação de proteínas.

O glicogênio e a trealose são considerados, conforme Amorim (2005) [10], os principais carboidratos de reserva, podendo ser utilizados como substratos para a fermentação, uma vez que são de natureza endógena, como constituintes da levedura, ou exógenas, como a sacarose, a glicose, a frutose e outros [11].

A trealose é um dissacarídeo não redutor composto por duas moléculas de glicose unidas por ligação do tipo $(\alpha-1,1)$ e ganhou interesse especial devido às suas propriedades multifuncionais [12]. Este metabólito constitui uma fonte de carbono e energia para microrganismos e vegetais, possuindo, ainda, uma ação osmoprotetora e desempenhando um importante papel fisiológico ao atuar na proteção ao estresse abiótico em um grande número de organismos [13].

$\mathrm{O}$ acúmulo da trealose e etanol podem variar conforme o tipo de estresse fermentativo aos quais as leveduras são submetidas durante o processo fermentativo [14]. Assim, estudos para a determinação de trealose, realizados em mosto, a base de caldo de cana são importantes, uma vez que este é utilizado na fermentação em usinas, possuindo como componente fundamental a sacarose. Ainda, entender o metabolismo de leveduras bem como a produção e o acúmulo dos metabólitos produzidos durante a fermentação pode ser uma ferramenta para auxiliar na escolha da levedura para o processo fermentativo. Deste modo, o presente estudo visa quantificar o perfil de acúmulo de trealose e etanol em linhagens industriais de Saccharomyces cerevisiae submetidas a diferentes condições de fermentação. 


\section{MATERIAL E MÉTODOS}

\subsection{Microrganismos utilizados}

As linhagens Fleischmann, Catanduva-1 e a Pedra-2 foram adquiridas por doação através da empresa LNF Latino Americana Biotecnologia Aplicada, localizada em Bento Gonçalves, RS. A linhagens Red Star gentilmente doada pela Lasaffre, França.

\subsection{Pré-inóculo e condições de cultivo}

O pré-inóculo foi preparado utilizando o meio de cultivo YPSAC 5\%, contendo: 1,0\% (m/v) de extrato de levedo; $1,0 \%(\mathrm{~m} / \mathrm{v})$ de peptona; $5,0 \%(\mathrm{~m} / \mathrm{v})$ sacarose; com $\mathrm{pH}$ ajustado para $5,0 \mathrm{com}$ ácido clorídrico $1 \mathrm{~N}$, sendo esterilizado por autoclavação $\left(120^{\circ} \mathrm{C}\right.$ por 20 minutos $)$. No meio YPSAC $5 \%$, foram adicionadas 0,10 gramas de leveduras liofilizadas e incubados por $24 \mathrm{~h}$ a $30^{\circ} \mathrm{C}$ a 200 rpm. Após o período de crescimento as células foram centrifugadas por 20 minutos $250 \mathrm{rpm}$, ressuspendidas e lavadas por três vezes consecutivas em solução salina $(0,85 \%)$ estéril, resultando em uma concentração de $10 \mathrm{mg} \mathrm{mL}$ de massa úmida.

\subsection{Condições fermentativas}

Os ensaios de fermentação foram realizados em mosto a base de caldo de cana esterilizado na concentração de $15{ }^{\circ}$ Brix sem correção do $\mathrm{pH}$, em erlenmeyers de $125 \mathrm{~mL}$, contendo $50 \mathrm{~mL}$ do mosto e incubados em estufa sem agitação a 30 e $40^{\circ} \mathrm{C}$, e alíquotas foram retiradas para quantificar o acúmulo de trealose e etanol nos tempos de 10, 20 e 40 horas.

\subsection{Métodos analíticos}

Para o processo de quantificação da trealose foi utilizado $1,0 \mathrm{~mL}$ da amostra, as quais foram coletadas, centrifugadas e lavadas por três vezes consecutivas em solução salina a $0,85 \%$. As células foram ressuspendidas em $1,0 \mathrm{~mL}$ de $\mathrm{Na}_{2} \mathrm{CO}_{3} 0,25 \mathrm{mmol} \mathrm{L}^{-1}$ e incubadas por 20 minutos em banho fervente. Após a centrifugação as amostras foram retiradas para determinação da trealose [15]. O ensaio enzimático foi realizado utilizando a enzima trealase obtida do fungo Humicola grisea, segundo o método descrito por Neves et al. (1994) [16]. Para a quantificação da trealose a condição reacional foi realizada em $100 \mathrm{~mL}$, composto por $25 \mathrm{~mL}$ de amostra, $12,5 \mathrm{~mL}$ de tampão de acetato $300 \mathrm{mM} \mathrm{pH} 5,5$ contendo $\mathrm{CaCl}_{2} 15 \mathrm{mM}, 12,5 \mathrm{~mL}$ de ácido acético $1 \mathrm{M}$ e $50 \mathrm{U}$ da enzima trealase, sendo incubada por uma hora a $40^{\circ} \mathrm{C}$ e interrompida com banho fervente por 10 minutos. A glicose proveniente da hidrólise da trealose foi dosada por Kit comercial (Labtest, Brasil). A trealose foi expressa como nmoles de trealose/mg de células seca.

A concentração do etanol foi determinada por meio de cromatógrafo a gás CG 3900 com detector de ionização de chama (Varian), utilizando para isso uma coluna capilar de sílica fundida de $30 \mathrm{~m}$ de comprimento (ZB-5). A condição cromatográfica empregada foi: volume de injeção $1 \mu \mathrm{L}$; razão e split, 1:20; e, temperatura do forno de $90^{\circ} \mathrm{C}$. As temperaturas do injetor e do detector foram de $240^{\circ} \mathrm{C}$. As amostras foram filtradas em ultra filtro de $0,22 \mu \mathrm{m}$.

\section{RESULTADOS E DISCUSSÃO}

A levedura Fleischmann apresentou o maior acúmulo de trealose em todos os tempos analisados, sendo que no tempo de 10 horas apresentou 100 nmoles de trealose $/ \mathrm{mg}$ de células seca na temperatura de $30^{\circ} \mathrm{C}$, quando comparada com as demais leveduras analisadas. Podemos observar que este acúmulo foi gradativo nos tempos analisados e na temperatura de $40^{\circ} \mathrm{C}$ foi mais expressivo. Possivelmente, o maior acúmulo deste carboidrato de reserva possa estar relacionado com a fisiologia desta levedura uma vez que a mesma não está adaptada para o estresse térmico das condições do processo fermentativo. A linhagem Catanduva-1 apresentou um maior acúmulo de trealose, de 110 nmoles de trealose $/ \mathrm{mg}$ de células seca a $40^{\circ} \mathrm{C}$ no tempo mais prolongado da fermentação. Para a levedura Red Star o acúmulo de trealose foi mais acentuado na temperatura de 
$40^{\circ} \mathrm{C}$, apresentando pico máximo de produção de 180 nmoles de trealose $/ \mathrm{mg}$ de células seca em 40 horas de fermentação (Figuras 1A, 1B e 1C). O acúmulo de trealose ocorreu no final da fase exponencial e início da fase estacionária, condição que pode ter sido causada devido à abundância de nutrientes da fonte de carbono extracelular, a reutilização da glicose em períodos de escassez ou pela alta temperatura e tempos prolongados de fermentação. Possivelmente, a sacarose pode interferir no acúmulo de trealose, uma vez que a levedura produz a enzima invertase que hidrolisa a sacarose em glicose sendo esta molécula metabolizada para a produção de etanol.

Em estudos realizados por Martins (2013) [17], que submeteu a S. cerevisiae ao estresse ácido a fim de analisar a mobilização de reservas energéticas, principalmente a trealose, observou que o consumo do carboidrato passou a ser ainda maior quando as células foram previamente submetidas a um estresse térmico subletal e coincidiu com as maiores taxas de viabilidade celular da levedura. Para Mahmud et al. (2010) [14], a trealose acumulada auxilia na resistência a múltiplos estresses, sendo que o aumento deste metabólito pela levedura provavelmente é uma forma de autoproteção ao estresse térmico a que é acometida durante o processo fermentativo. Ademais, a trealose e o glicogênio são, primariamente, considerados como carboidratos de reserva, mas também podem estar envolvidos em outras atividades fisiológicas [18]. Neste contexto, a trealose desempenha tanto a função de carboidrato de reserva como de proteção contra estresses [19, 20].

Observou-se neste estudo uma variação no acúmulo de trealose, evidenciando-se uma resposta metabólica das leveduras industriais em relação ao estresse sofrido em diferentes temperaturas e tempos prolongados, situação que pode ocasionar a perda da capacidade fermentativa e, por consequência, na produção de etanol.
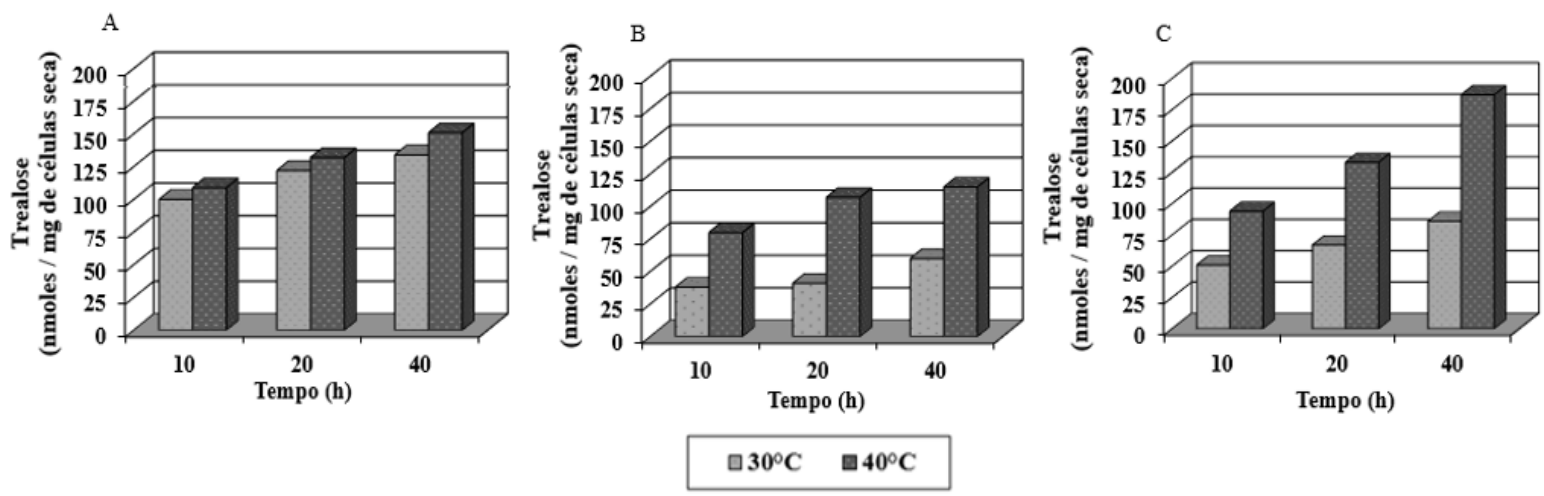

Figura 1: Avaliação do perfil acúmulo de trealose das leveduras Fleischmann (A), Catanduva-1 (B) e Red Star $(C)$ cultivadas em mosto a base de caldo de cana na concentração de $15{ }^{\circ}$ Brix nas temperaturas de 30 e $40^{\circ} \mathrm{C}$ por diferentes tempos de fermentação.

A linhagem Fleischmann apresentou a maior concentração de etanol com 9,0\% (v/v) em 20 horas de fermentação a $30^{\circ} \mathrm{C}$, contudo, quando cultivada à $40^{\circ} \mathrm{C}$ foi observada uma queda acentuada na concentração de etanol, chegando a 4,0\% (v/v) no tempo de 40 horas. Foi observado que a alta temperatura e tempos prolongados da fermentação ocasionaram uma queda na produção de etanol. Possivelmente tais fatores podem ser considerados estressantes, o que pode ter causado a mudança na rota metabólica do microrganismo, tendo em vista que esta é uma linhagem de panificação. A levedura Catanduva-1 apresentou uma maior concentração de etanol, de 13,8\% (v/v) em 40 horas a $30^{\circ} \mathrm{C}$. Foi possível observar que em $40^{\circ} \mathrm{C}$ e nos tempos mais prolongados da fermentação ocorreu uma perda deste metabólito. Para a linhagem Red Star a melhor concentração foi de $10 \%$ (v/v) de etanol nos tempos de 10 e 20 horas de fermentação a $30^{\circ} \mathrm{C}$, sendo que a $40^{\circ} \mathrm{C}$ a levedura apresentou perfil metabólico semelhante a Catanduva-1 (Figuras 2A, 2B e 2C). 

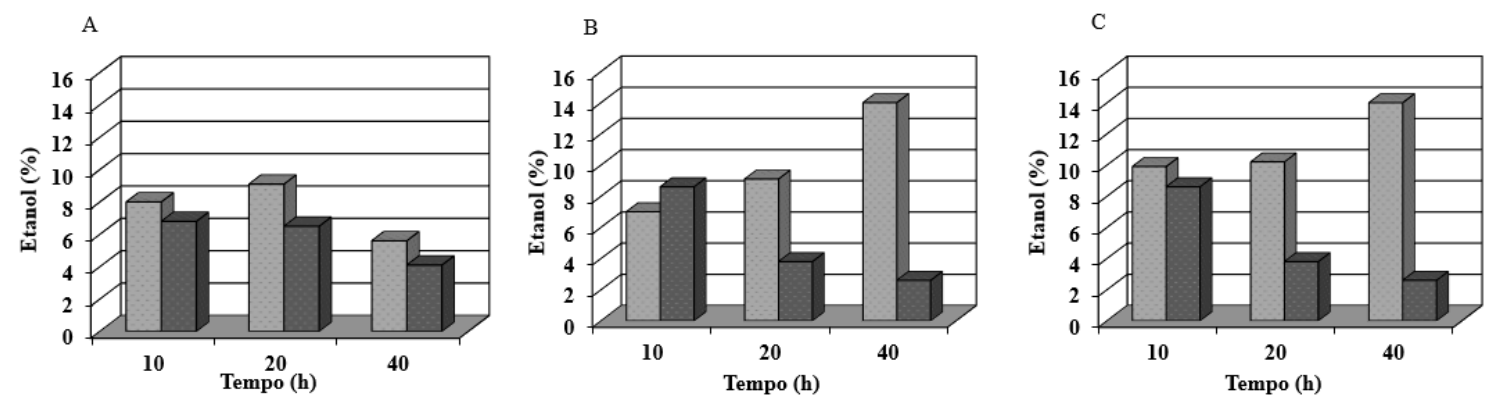

$\square 30^{\circ} \mathrm{C} \quad \square 40^{\circ} \mathrm{C}$

Figura 2: Análise da concentração de etanol das leveduras Fleischmann (A), Catanduva-1 (B) e Red Star (C) cultivadas em mosto a base de caldo de cana na concentração de $15^{\circ}$ Brix nas temperaturas de 30 e $40^{\circ} \mathrm{C}$ por diferentes tempos de fermentação.

Em seus estudos, dos Santos et al. (2012) [21], utilizando a levedura Catanduva-1 cultivada em mosto de cana-de-açúcar como substrato, nas concentrações de 18,22 e $25^{\circ}$ Brix e nas temperaturas de 30 e $40^{\circ} \mathrm{C}$ em diferentes tempos de cultivo, observaram que a levedura apresentou produção de etanol de $3,4 \%$ e $4,5(\mathrm{v} / \mathrm{v})$, nas concentrações de 18 e $22^{\circ}$ Brix em 20 de fermentação a $30^{\circ} \mathrm{C}$. Em tempos mais prolongados de fermentação e a $40^{\circ} \mathrm{C}$ ocorreu uma perda na concentração deste metabólito, assim como observado neste trabalho.

Em estudo realizado por Santos et al. (2018) [22], com a levedura FT-858 cultivada em caldo de cana e de sorgo sacarino, sendo 7,5\% (v/v) em caldo de cana e 7,0\% (v/v), foi observado que as linhagens Catanduva-1 quando cultivada em mosto a base de caldo de cana na temperatura de $30^{\circ} \mathrm{C}$ apresentaram uma maior produção de etanol.

Santos Moreira et al. (2015) [23], analisando a performance fermentativa das leveduras Catanduva-1, Pedra-2, Red Star e Ragi Instam, utilizando mosto a base de caldo de cana com concentrações de $12,15,24$ e $30^{\circ}$ Brix à temperatura de $30^{\circ} \mathrm{C}$, observaram que as leveduras apresentaram melhor taxa de viabilidade celular em torno de $95 \%$, para todas as linhagens quando cultivadas a $15^{\circ}$ Brix a resposta fisiológica refletiu na produção de etanol, ficando em 8,5\% (v/v), valores estes inferiores aos encontrados neste estudo que foram para a levedura Fleischmann $9 \%$ (v/v), para a Catanduva-1 13,8\% (v/v) e Red Star 10\% (v/v).

\section{CONCLUSÃO}

O perfil do acumulo de trealose e a produção de etanol foram inversamente proporcionais em relação às leveduras analisadas. A linhagem Fleischmann apresentou maior acumulo de trealose em ambas nas temperaturas de 30 e $40^{\circ} \mathrm{C}$ e por consequência menor produção de etanol, mostrando ser mais sensível a ação do estresse fermentativo. A Catanduva-1 e a Red Star apresentaram um acúmulo gradativo de trealose e uma perda de etanol na temperatura mais elevada e em tempos prolongados de fermentação.

\section{AGRADECIMENTOS}

Agradecimentos a Fundect pelo apoio financeiro e a Empresa LNF pela concessão das linhagens de leveduras.

\section{REFERÊNCIAS BIBLIOGRÁFICAS}

1. Andrietta MGS, Steckelberg CE, Andrietta SR. Bioetonol Bioetanol- Brasil 30 anos na vanguarda. MultiCiências - UNICAMP. 2006;7:1-16.

2. Basso LC, Amorim HV, Oliveira AJ, Lopes ML. Yeast selection for fuel ethanol production in Brazil. FEMS Yeast Research. 2008:1155-1163, doi:https://doi.org/10.1111/j.1567-1364.2008.00428.x 
3. Bai FW, Anderson WA, Moo-Young M. Ethanol fermentation technologies from sugar and starch $\begin{array}{lll}\text { feedstocks. } & \text { Biotechnology 2008;26:89-105, }\end{array}$ doi:https://doi.org/10.1016/j.biotechadv.2007.09.002.

4. Oliva-Neto P, Dorta C, Carvalho AFA, Lima VMG, Silva DF. The Brazilian technology of fuel ethanol fermentation-yeast inhibition factors and new perspectives to improve the technology. Materials and Processes for Energy: Communicating Current Research and Technological Developments. 2013;1:371379.

5. Barbosa HS. Fermentação de mosto com alto teor de sacarose para a produção de bioetanol combustível por diferentes linhagens de Saccharomyces cerevisiae usando alta densidade celular. Dissertação (Mestrado) - Universidade Estadual Paulista Júlio de Mesquita Filho - Instituto de Química. Araraquara - SP; 2013. $91 \mathrm{p}$.

6. Pereira FB, Guimarães PMR, Teixeira JA, Domingues L. Robust industrial Saccharomyces cerevisiae strains for very high gravity bio-ethanol fermentations. Journal of Bioscience and Bioengineering. 2011;130-136, doi:https://doi.org/10.1016/j.jbiosc.2011.03.022.

7. Zhao XQ, Bai FW. Mechanisms of yeast stress tolerance and its manipulation for efficient fuel ethanol production. Journal Biotechnology. 2009;144:23-30, doi:https://doi.org/10.1016/j.jbiotec.2009.05.001.

8. François JM, Walther T, Parrou JL. Genetics and regulation of glycogen and trehalose metabolism in Saccharomyces cerevisiae. Microbiology Stress Tolerance for Biofuels. 2012;22:32-35.

9. Trevisol ETV, Panek AD, Mannarino SC, Eleutherio ECA. The effect of trehalose on the fermentation performance of aged cells of Saccharomyces cerevisiae. Applied microbiology and biotechnology. 2011;90:697-704, doi:http://sci-hub.tw/10.1007/s00253-010-3053-x.

10. Amorim HV. Fermentação Alcoólica: Ciência e Tecnologia. Piracicaba. Fermentec. SãoPaulo; 2005, 448 p.

11. Santos JRA, De Gusmão NB, Gouveia ER. Seleção de linhagem industrial de Saccharomyces cerevisiae com potencial desempenho para a produção de etanol em condições adversas de temperatura e de agitação. Revista Brasileira de Produtos Agroindustriais. 2010;12(1):75-80.

12. Gancedo C, Flores CL. The importance of a functional trehalose biosynthetic pathway for the life of yeasts and fungi. FEMS Yeast Research. 2004;4:351-359, doi:https://doi.org/10.1016/S15671356(03)00222-8.

13. Zaparty M, Hagemann A, Brasen C, Hensel R, Lupas AN, Brinkmann H, Siebers B. The first prokaryotic trehalose synthase complex identifiedin the hyperthermophilic crenarchaeon Thermoproteustenax. PLOS ONE. 2013;8(4):1-11, doi:https://doi.org/10.1371/journal.pone.0061354.

14. Mahmud SA, Hirasawa T, Shimizu H. Differential importance of trehalose accumulation in Saccharomyces cerevisiae in response to various environmental stresses. Journal of Bioscience and Bioengineering. 2010;109(3):262-266, doi:https://doi.org/10.1016/j.jbiosc.2009.08.500.

15. Parrou JL, Teste MA, François J. Effects of various types of stress on the metabolism of reserve carbohydrates in Saccharomyces cerevisiae: genetic evidence for a stress induced recycling of glycogen and trehalose. Microbiology. 1997;143:1891-1900.

16. Neves MJ, Terenzi HF, Leone FA, Jorge JA. Quantificaction of trehalose in biological samples witch a conidial trehalases from the thermophilic fungus Humicola grisea var. thermoidea. World Journal Microbiology. Biotechnology. 1994;10:17-19.

17. Martins RL. Importância das reservas energéticas para a resposta ao estresse ácido em Saccharomyces cerevisiae. Dissertação (Mestrado em Biotecnologia) - Núcleo de Pesquisas em Ciências Biológicas, Universidade Federal de Ouro Preto - MG; 2013.

18. François J, Parrou JL. Reserve carbohydrates metabolism in the yeast Saccharomyces cerevisiae. FEMS Microbiology Letters. 2001;25:125-145, doi:https://doi.org/10.1111/j.1574-6976.2001.tb00574.x.

19. Chen C, Ji R, Schwab DJ. A model study of the coupled biological and physical dynamics in Lake Michigan. Ecological modelling. 2002;152:145-168, doi:https://doi.org/10.1016/S0304-3800(02)000261.

20. Garre E, Matallana E. The three trehalases Nth1p, Nth2p and Ath1p participate in the mobilization of intracellular trehalose required for recovery from saline stress in Saccharomyces cerevisiae. Microbiology. 2009;155:3092-3099.

21. dos Santos NP, da Silva GA, Lima Cardoso CA, Batistote M. Cell Stress Profile During Metabolite Production by Saccharomyces cerevisiae Catanduva-1 in Sugarcane Wort. Orbital: The Electronic Journal of Chemistry. 2012;10(1):31-36, doi:http://dx.doi.org/10.17807/orbital.v10i1.1029.

22. Santos MSM, Lima Cardoso CA, Silva EM, Batistote M. Potential of Saccharine Substrates for Ethanol Production. Orbital: The Electronic Journal of Chemistry. 2018;10(1):14-21, doi:http://dx.doi.org/10.17807/orbital.v10i1.1013.

23. Santos Moreira C, Mascarenhas Santos MDS, Soares Barro N, Lima Cardoso CA, Batistote M. Análise dos parâmetros morfofisiológicos de linhagens de leveduras industriais com potencial biotecnológico 
para a produção de etanol. Ciência e Natura. 2015;37(3):55-63, doi:http://dx.doi.org/105902/2179460X18107. 